\title{
INTEGRANDO VOCABLOS: IDENTIDAD Y EXTRANJERO. EL CASO DE LOS HISPANOS EN ESTADOS UNIDOS
}

\section{RESUMEN:}

El tema a tratar es la identidad y su vinculación con el concepto de extranjero. Se comienza precisando a qué se refiere el término identidad, para pasar a conceptualizar el término extranjero según Simmel, Bauman y Schutz. Se coloca al inmigrante como ejemplo de extranjero y se toma la inmigración hispana a los Estados Unidos como ejemplo del fenómeno de la mediación de identidades, sus culturas y sus conflictos. Frente al aumento de la población hispana/latina en dicho país, se enfatiza la actitud de oposición, rechazo y temor a la alteridad y a la diferencia, por parte de Huntington.

PALABRAS CLAVE:

Identidad - Extranjero - Migración hispana - Alteridad.

\section{ABSTRACT:}

The subject is about identity and its linking with the concept of foreigner. It begins by specifying the meaning of the term identity, to continue explaining foreigner's term according to Simmel, Bauman and Schutz. The immigrant is compared to the foreigner; using the Hispanic immigration to the United States as an example of the phenomenon of the mediation of identities, their cultures and their conflicts. It emphasizes the Huntington's attitude concerning the latin/hispan population in this country, which is an aproach showing opposition, rejection and fear from otherness and difference.

\section{KEY WORDS}

Identity - Foreigner - Hispanic migration - Otherness. 
El tema específico de esta ponencia es la identidad frente al extranjero, colocando a la inmigración hispana a los Estados Unidos como ejemplo del fenómeno de la mediación de identidades, sus culturas y sus conflictos.

A partir de la modernidad, la complejidad social se expresa como una pluralización del ámbito de la vida dejando atrás un sistema único de referencias. El individuo se confronta con un caleidoscopio de experiencias y sentidos que, lejos de anclarlo en un determinado dominio social, le amplían las posibilidades de elección.

En la fase histórica presente, por muchos denominada la era de la globalización y por algunos más apresurados, la posmodernidad, se aboga por la uniformidad a la vez que se enarbola el estandarte del pluralismo que promueve la diferencia, la alteridad y lo heterogéneo. Cabe señalar que muchos son los autores ${ }^{1}$ que concuerdan en el hecho de que la globalización viene acompañada de la bipolaridad particular/universal, regional/global, nacional/mundial; la globalización y la búsqueda de identidad propia; globalización frente a fragmentación; paradoja de las tendencias a vivir en un mundo sin fronteras junto a la afirmación de identidades comunitarias, lingüísticas y religiosas, entre otras.

Esta bipolaridad concuerda y se acomoda con el tema de las identidades en la actualidad: por un lado se pretende homologar culturas e individuos a nivel mundial, lo cual conduciría a equiparar identidades en una sola pertenencia, mientras que la contraparte defiende la diversidad identitaria de cada grupo, pueblo y/o etnia.

La diversidad de los grupos humanos siempre ha estado presente, pero sin duda ha sido en las últimas dos décadas del siglo pasado cuando la preservación identitaria ha tomado grandes dimensiones. Es precisamente la intensa interpenetración de grupos y de culturas la marca característica de finales del siglo XX.

Abordemos pues, el tema de la identidad misma, mediante el simple ejercicio de construir una cadena de enlaces usando el diccionario de sinónimos (palabras que tienen un mismo significado o que no siendo siempre equivalentes, sí son similares). Al tomar la palabra "identidad" como génesis se obtuvieron los siguientes vocablos: "igualdad" y "equivalencia"; "asemejar" y "reconocer"; "confundirse", "coincidir" y "hermanarse"; "incumbir", "atañe", "concerniente", "relativo" y "referido"; "propio", "peculiar", "característico", "natural", "mismo". Apareció el vocablo "propiedad" que resultó equivalente a "pertenencia", "posesión" y "dominio". Esto condujo a los términos "protegido", "defendido", "resguardado", "seguro", "amparado". Finalmente rebotaron las palabras "cobijarse", "resguardarse", "guarnecerse" y "abrigarse".

Este conjunto de palabras presentan una visión general de lo que la identidad nos brinda como individuos sociales: nos relaciona con lo semejante y lo parecido, nos da sentido de pertenencia y nos permite sentirnos resguardados y protegidos. Nos proporciona seguridad individual y colectiva.

Claro que la identidad, para ser reconocida, viene invariablemente acompañada de la diferencia. Los opuestos "ellos" y "nosotros" conforman la esencia de las diferenciaciones identitarias. El "nosotros" produce automáticamente un "ellos", ya que para poder saber quién pertenece al "nosotros" se debe

\footnotetext{
${ }^{1}$ Beck, 1998, p. 34; Villoro, 1998; Clark, 1997; Pozas, 1999, pp. 170-71; Olivé, 1999, pp. 31-35; Giménez, 1996, pp. 11-24; García Canclini, 1999, pp. 48-49; Castells, 1999.
} 
definir quién no lo es, y quién no lo es concierne al "ellos"; como bien lo define el sociólogo George Simmel: "la coincidencia frente a la diferencia"?

Asimismo, los términos "ellos" y "nosotros" sólo tienen sentido juntos y dentro de su oposición mutua. ${ }^{3}$ Si uno no se opone al otro sería imposible definir la identidad propia.

Al volver al diccionario de sinónimos, tarea semejante a la anterior se realizó con el vocablo "extranjero" obteniendo los siguientes términos: "extraño", "forastero" y "exótico". La palabra "extrañamiento" como sinónimo de "exilio", "deportación”, "destierro", "expatriación” y "proscripción”. "Extrañeza" se mostró similar a "novedad", "rareza” y "originalidad", mientras que, finalmente, "extraño" resultó ser equivalente de "raro", "insólito", "extravagante", "impropio", "ajeno", "exótico" y, cerrando el círculo, nuevamente obtuvimos la palabra "extranjero". Escrutando el término "forastero" se encontró que su sinónimo era "foráneo", "ajeno", "extraño", "extranjero” y "alienígeno".

Aunados a los vocablos obtenidos del diccionario, se pueden agregar otros términos comúnmente utilizados en las ciencias sociales relacionados con el extranjero y que indican su condición de marginado, de outsider, de outcast-proscrito, de paria, de desterrado, de excluido, de exiliado, de aislado. Es el Otro, la alteridad, el diverso, el raro, el innombrable, el desconocido, el que está fuera de, el errante, el nómada, el particularista, el negado, el desarraigado, el sin patria o expatriado.

Todas ellas en conjunto parecieran denotar a un sujeto - el extranjero - vacío de identidad, por lo tanto, vacío de pertenencia y de seguridad. ¿Será el extranjero aquel que no tiene identidad? ¿O es que su identidad no encuentra cabida o aceptación en la sociedad en que se encuentra?

Entonces, cabe cuestionarse qué significa el ser extranjero. La condición de extranjería se debe a múltiples razones, no únicamente a no ser nativo y/o ciudadano del país en el que se encuentra (ésta sería la definición legal habitual del término extranjero) sino a ser representante de la alteridad en todas sus manifestaciones: racial, religiosa, étnica, de estatus social y económico, entre otras. Es decir que, en circunstancias concretas y puntuales, ciertos individuos y grupos pueden ser nativos, contar con la ciudadanía del país donde nacieron, pero sólo por el hecho de pertenecer a colectivos particulares que representan lo diverso ante la óptica de la sociedad mayoritaria en la cual están insertos, pueden llegar a ser categorizados como extranjeros, y por ende, ser excluidos. El ejemplo clásico del extranjero es el individuo y/o grupo judío. De acuerdo a Bauman y Simmel es aquel que no vuelve a su lugar de origen pero tampoco pasa a pertenecer al grupo mayoritario; es el hombre intermedio.

Schutz califica al extranjero (a quien él denomina forastero) como una persona adulta, perteneciente a nuestra época y civilización, que trata de ser definitivamente aceptada o a lo menos tolerada por el grupo al que se aproxima. Este autor, al igual que Simmel, considera al inmigrante como un claro ejemplo del extranjero. Es precisamente extranjero, de acuerdo a Simmel, aquel emigrante en potencia que, aunque se haya detenido, no se ha asentado completamente: "aquel que hoy llega y mañana se establece". Es quien representa una nueva y específica forma de interacción en las sociedades modernas, caracterizado por su natural carencia de suelo, no sólo en el sentido físico, sino también en el sentido figurativo de una vida que se fija, si no en un punto del espacio, al menos en un punto ideal del ambiente social.

\footnotetext{
${ }^{2}$ Simmel, 1908, pp. 59-65.

${ }^{3}$ Bauman, 1990, pp. 57-72.
}

CUADERNOS JUDAICOS-ISSN: 0718-8749

No 26, diciembre 2009 
Si bien, ambos autores - Simmel y Schutz - presentaron al inmigrante como el extranjero durante la primera mitad del siglo XX, 1908 y 1944 respectivamente; muchos de esos argumentos siguen conservando gran validez a principios del siglo XXI.

De esta forma, vamos a referirnos aquí al extranjero como al inmigrante, quien en muchas ocasiones es descrito como aquel individuo que quiere asimilarse, pero no le es posible: siempre quedan residuos de su antigua identidad, particularmente cuando la sociedad o el grupo al que desea asimilarse no lo acepta en su totalidad. Comúnmente ocurre que por más que lo intente, su asimilación sea vista como burda y nunca completa.

Bauman y Schutz, aunado a lo anterior, concuerdan en el hecho de que al extranjero se le imputa una dudosa lealtad. Esto se da cuando el extranjero-inmigrante no quiere o no puede sustituir totalmente la pauta cultural de su grupo de origen por la adquirida. Con esto pasa a ser un hombre marginal, un híbrido cultural que vacila entre dos pautas diferentes de vida grupal, sin saber a cual de ellas pertenece.

Evidentemente cabe recalcar que no todos aquellos que se quieren adaptar y acoplar en su totalidad a un grupo que no es originalmente el suyo, fracasan en el intento. Por el contrario, muchos son los individuos y grupos que han realizado con éxito su incorporación a la sociedad receptora y que no han experimentado la extranjería a la que se alude en estos párrafos y quienes, inclusive, por su cantidad pasan a representar fenómenos colectivos.

Un ejemplo palpable del proceder del extranjero-inmigrante son los hispanos o latinos que cruzan la frontera a los Estados Unidos, básicamente con intenciones de mejorar sus condiciones de vida. Ya sea de forma ilegal o como la ley lo acredita, gran parte de estos inmigrantes comúnmente no regresan a sus países de origen (principalmente de México y Centro América) y se establecen en los Estados Unidos. Ya en el nuevo espacio la mayoría de ellos abriga la intención de mantener su identidad original y transmitirla a las generaciones futuras. Aunque ya son varias las generaciones nativas, los hispanos, que son actualmente la mayor minoría en los Estados Unidos (representaban un $14 \%$ de la población total en el año 2006), siguen siendo considerados "extranjeros" por muchos estadounidenses, es decir, son diferentes a aquellos estadounidenses que se dicen originales. ${ }^{4}$

En tiempos recientes, aunque los Estados Unidos ensaya un giro hacia la retórica de lo multicultural, del bilingüismo, de la doble ciudadanía y de la acción afirmativa, y pone en evidencia una reciente apertura en el debate relativo con la incorporación del inmigrante bajo una óptica diferente a la política asimilacionista del melting pot (crisol de razas), siguen habiendo voces en su interior que se rebelan ante esta nueva política multicultural.

En referencia a una de estas voces y en relación particular con el inmigrante hispano en los Estados Unidos, se debe mencionar a Samuel Huntington y su libro Quiénes Somos: Los desafíos a la identidad nacional americana, publicado en el 2004. Huntington, reconocido académico de Harvard, es autor del Choque de las civilizaciones, que aborda el tema de la contienda entre el Islam y Occidente, libro muy comentado, particularmente a partir del 11 de septiembre de 2001 (9/11).

Pero aboquémonos a Quiénes somos... que trata lo que este autor considera ser la nueva amenaza que recae sobre el país más poderoso del planeta: la inmigración hispana, particularmente la mexicana que, a su modo de ver, es capaz de terminar con el predominio de la cultura americana, es decir, la sociedad WHASP.

\footnotetext{
4 Con esto se hace referencia específica a los anglosajones o, como ellos se autodenominan, WHASP (sigla de white, anglosaxon, protestant - blanco, anglo parlante y protestante), quienes se atribuyen ser los americanos originales cuando realmente los originarios son las tribus indígenas - hoy concentradas en las reservaciones indias.
} 
Según Huntington, la contigüidad (países vecinos), el número (gran cantidad de flujo migratorio), la ilegalidad, la concentración regional y la persistencia histórica (plan de recuperar los territorios antaño pertenecientes a México) son factores presentes en el grupo mexicano inmigrante, los que contribuyen a imposibilitar la asimilación de este grupo; marcando de esta manera las diferencias con los inmigrantes europeos y canadienses de épocas pasadas quienes lograron asimilarse satisfactoriamente al american way of life; inmigración hoy reemplazada por los asiáticos y los latinoamericanos.

Este académico argumenta que si se reduce el número de inmigrantes hispanos también disminuirían de manera positiva los debates en cuanto al uso y oficialidad del idioma español y la educación bilingüe; la polémica en lo relativo a las prestaciones sociales, tales como la salud y la educación y los debates acerca de si estos inmigrantes implican una carga económica para los gobiernos estatales y el federal, entre otras. Huntington considera que la división ya existente entre los hispanoparlantes y los angloparlantes refleja una amenaza potencial a la integridad cultural y posiblemente política de los Estados Unidos.

Las opiniones vertidas por este autor reflejan la existencia de una sociedad con grupos dominantes mayoritarios y grupos minoritarios, de valores culturales y elementos identitarios netamente diferenciados. Estas diferenciaciones culturales son, en parte, origen de los conflictos de dominación, de confrontación y también causa de diferentes movimientos de incorporación (o de intentos de ello) en el grupo minoritario o algunos de sus miembros.

Finalmente se recupera la relación entre identidad y extranjería, para volver a la pregunta de si será extranjero aquel que no tiene identidad.

Sin duda el extranjero o forastero, sea cual fuere la condición y naturaleza de su alteridad, conlleva una identidad referencial. La pregunta más bien debe ser enfocada en el hecho de que su identidad, la del denominado extranjero, no encuentra entrada, aceptación ni reconocimiento en la sociedad en que se ubica. Tanto si quiere mantener esta identidad original o si desea asimilarse al nuevo espacio, serán las condiciones sociales, políticas y económicas bajo un contexto histórico determinado quienes van a definir las actitudes de la sociedad receptora frente al Otro y su capacidad de asumir la alteridad.

A modo de conclusión, retomo la búsqueda realizada en el diccionario de sinónimos. Al llegar al término "extrañar" resaltaron las palabras "admirar", "chocar", "sorprender", "asombrar". Al leer esto me hice la siguiente pregunta: ¿Será que lo que uno no conoce, lo no familiar, lo no convencional, lo diferente, lo extraño, puede ser considerado como signo y símbolo de admiración y sorpresa, pero también como señal de choque y por ende, de confrontación?

CUADERNOS JUDAICOS-ISSN: 0718-8749

No 26, diciembre 2009 


\section{REFERENCIAS BIBLIOGRÁFICAS}

BECK, U., ¿Qué es la Globalización?. Ediciones Paidós Ibérica. 1998.

BAUMAN, Zygmunt, Pensando Sociológicamente. Capitulo Tres: "Los Extranjeros", Ediciones Nueva Visión. 1990. pp. 57-72.

CASTELLS, M., La era de la información: economía, sociedad y cultura. Volumen II: El poder de la Identidad. Siglo XXI Editores. 1999-

CLARK, I., Globalization and Fragmentation. Oxford Universiy Press, 1997. pp. 1-31.

GARCÍA CANCLINI, N., La Globalización Imaginada. Editorial Paidós Mexicana, S.A. 1999.

GIMÉNEZ, G., "La identidad social o el retorno del sujeto en sociología. Identidad: Análisis y teoría, simbolismo, sociedades complejas, nacionalismo y etnicidad." EN: MÉNDEZ Y MERCADO, Leticia I. (Coord.) III Coloquio Paul Kirchhoff, UNAM. 1996. pp. 11-24.

HUNTINGTON, S., Quiénes Somos: Los desafíos a la identidad nacional americana. Editorial Paidós. 2004.

OLIVÉ, L., Anthropos: Multiculturalismo y Pluralismo. Editorial Paidós Mexicana y la Facultad de Filosofía y Letras, UNAM. 1999.

POZAS HORCASITAS, R., "La Integración Global". EN: VALERO R. (coord.). Globalidad: Una Mirada Alternativa. Centro Latinoamericano de la Globalidad: México. 1999. pp. 167-200

ROITMAN, D., "Múltiples formas de ser extranjero en la modernidad" EN: GUITÍAN GALÁN, M y ZABLUDOVSKY KUPERO, G. (Coord.). Sociología y modernidad tardía: entre la tradición y los nuevos retos. Ediciones Casa Juan Pablos y la UNAM, Facultad de Ciencias Políticas y Sociales. México; 2003. pp. 201-221.

SCHUTZ, A., "El Forastero" [1944] EN: TERRÉN, Eduardo (Ed.) Razas en conflicto, Editorial Anthropos. 2002 pp. 144-156.

SIMMEL, G., "El extranjero como forma sociológica" [1908] EN: TERRÉN, Eduardo (Ed.), Razas en conflicto, Editorial Anthropos. 2002 pp. 59-65.

VILLORO, L., Estado Plural, pluralidad de culturas. Editorial Paidós. 1998. pp. 63-78. 